\title{
Is it really a seizure? The challenge of paroxysmal nonepileptic events in young infants
}

\author{
Seung Yeon Jung, $\mathrm{MD}^{1}$, Joon Won Kang, MD, $\mathrm{PhD}^{2}$ \\ ${ }^{1}$ Department of Pediatrics, Chungnam National University Hospital, Daejeon, Korea; ${ }^{2}$ Department of Pediatrics \& Medical Science, Chungnam National University \\ School of Medicine, Daejeon, Korea
}

Paroxysmal nonepileptic events (PNE) comprise of a variety of nonepileptic behaviors and are divided into various types. A more accurate diagnosis is possible by examining the video clip provided by the caregiver. In infants, physiologic PNE accounts for the majority of the PNE. It is important to exclude epilepsy, for which blood tests, electroencephalography, and imaging tests can facilitate differential diagnosis. Since most PNE have a benign progress, symptoms often improve with age and without special treatment. Therefore, it is important to reassure the caregivers after making an accurate diagnosis.

Key words: Nonepileptic seizure, Seizure, Infant, Epilepsy, Electroencephalography

\footnotetext{
Key message

- Paroxysmal nonepileptic events (PNE) in infancy exhibit various behaviors, mostly accompanied by neurological comorbidities and usually disappear naturally.

- Video clips are helpful for accurate diagnosis; video electroencephalography monitoring is a gold standard.

Breath-holding spells in late infancy may be associated with iron and the success rate of iron treatment is 59\%-95\%.

- Jitteriness in newborns, shivering in early infancy, and breathholding spells in late infancy are common PNE.
}

\section{Introduction}

A seizure is not a rare symptom and it is experienced by approximately $10 \%$ of the people worldwide. ${ }^{1)}$ In the case of children, the greatest concern of caregivers is whether the seizure might progress to epilepsy. Epilepsy is defined as a disorder of the brain characterized by an enduring predisposition to generate epileptic seizures. An epileptic seizure is a transient occurrence of signs and/or symptoms due to abnormal excessive or synchronous neuronal activity in the brain. ${ }^{2)}$ The most basic element of the diagnosis is to ascertain whether the symptom is a true epileptic seizure. Symptoms resembling seizures are just one behavior, but not a seizure. Therefore, the accurate diagnosis of a seizure is essential for the diagnosis of epilepsy and subsequent treatment. ${ }^{3-6}$ )

Paroxysmal nonepileptic events (PNE) collectively refer to symptoms that display a behavior similar to that of a seizure, but this condition is not a true epileptic seizure. ${ }^{7-9)}$ Previous studies have reported that approximately $12 \%-40 \%$ of suspected seizures were PNE (Table 1). These are broadly divided into psychogenic PNE and nonpsychogenic (physiologic) PNE, of which nonpsychogenic PNE is dominant in young infants. ${ }^{7,10}$ When young infants display abnormal behaviors, their caregivers tend to panic, fearing seizure and epilepsy. Accurate diagnosis can thus reduce the unnecessary use of antiepileptic drugs and ease the anxiety of caregivers. This paper aims to explore PNE in young infants in terms of pathophysiology, diagnostic strategy, and representative PNE.

\section{Pathophysiology}

The mechanism of PNE is not yet fully known. There are many different types of PNE, and their pathogenesis is difficult to perfectly understand. In human brain development, the infantile period is characterized by dynamic changes especially in synaptic organization and myelination. ${ }^{11)}$ The newborn is capable of only little movements such as swallowing and sucking, but as the developmental process progresses, the infant can walk and play by 1 year of age. Kuiper et al. ${ }^{12)}$ found that hyperkinetic (choreatic, myoclonic, and dystonic) movements are transiently observed in 0-3 months of age. After 6 months of age, choreatic and myoclonic movements disappear with sustained dystonic feature. This phenomenon was explained by the development of underlying motor centers and networks connecting the immature basal ganglia, cerebral cortex, and cerebellum. PNE might be explained by an immature and developing infantile brain. Most PNE are resolved as the child grows and as the brain matures. Some authors called PNE as "developmental and benign movement disorders."13)

Like other paroxysmal movement disorders, some PNE are

\footnotetext{
Corresponding author: Joon Won Kang, MD, PhD. Department of Pediatrics, Chungnam National University Hospital, Chungnam National University School of Medicine, 282 Munwha-ro, Jung-gu, Daejeon 35015, Korea 
Table 1. Studies of paroxysmal nonepileptic events including infants

\begin{tabular}{|c|c|c|c|c|c|c|}
\hline Study & Mean age & Case size & Case selection & $\begin{array}{l}\text { Diagnostic } \\
\text { modality }\end{array}$ & $\begin{array}{l}\text { Diagnosed as } \\
\text { PNE, n (\%) }\end{array}$ & $\begin{array}{l}\text { No. of PNE patients } \\
\text { with neurological } \\
\text { comorbidities }^{b)}, \mathrm{n}(\%)\end{array}$ \\
\hline Park et al. $^{33)}(2015)$ & $<18 \mathrm{yr}$ & 887 & Performed video-EEG & EEG & $\begin{array}{l}141(15.9) \\
50(<6 y r)^{a)}\end{array}$ & $\begin{array}{l}62(44.0) \\
26(52.0,<6 \mathrm{yr})\end{array}$ \\
\hline Kim et al. ${ }^{34)}$ (2012) & $<19 \mathrm{yr}$ & 1,108 & Performed video-EEG & EEG & $\begin{array}{l}143(12.9) \\
35(<1 \mathrm{yr})^{\mathrm{a})}\end{array}$ & $64(44.8)$ \\
\hline Hamiwka et al. ${ }^{35)}$ (2007) & $8 \mathrm{yr}(4 \mathrm{wk}-17 \mathrm{yr})$ & 127 & Referred with first seizure & $\begin{array}{c}\text { Clinical } \\
\text { characteristic }\end{array}$ & $\begin{array}{l}31(24) \\
11(31,<2 y r)^{a)}\end{array}$ & Not specified \\
\hline Beach and Reading ${ }^{5)}$ (2005) & $4 w k-16 y r$ & 684 & Suspected epileptic seizure & EEG & $272(39.8)$ & Not specified \\
\hline Kotagal et al. ${ }^{9)}$ (2002) & $8 w k-18 y r$ & 883 & Performed video-EEG & EEG & $\begin{array}{l}134(15.2) \\
26(<5 y r)^{a)}\end{array}$ & $59(44.0)$ \\
\hline Bye et al. ${ }^{36)}(2000)$ & $2 w k-17 y r$ & 666 & Performed video-EEG & EEG & $285(42.8)$ & $122(42.8)$ \\
\hline Desai and Talwar ${ }^{37)}$ (1992) & 7.37 yr (0.12-19 yr) & 124 & Performed video-EEG & EEG & $27(21.8)$ & $19(70.0)$ \\
\hline Bye and Nunan ${ }^{38)}$ (1992) & $3 w k-17 y r$ & 186 & Performed video-EEG & EEG & $74(39.8)$ & $26(35.1)$ \\
\hline
\end{tabular}

EEG, electroencephalography; PNE, paroxysmal nonepileptic events.

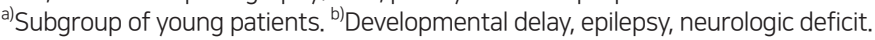

also associated with genetic mutations. ${ }^{14)}$ The CACNA1A gene encodes the $\alpha 1 \mathrm{~A}$ subunit of the voltage gated calcium channel. The mutation of this gene is associated with early infantile epileptic encephalopathy, episodic ataxia, migraine, and spinocerebellar ataxia. Paroxysmal tonic upgaze with ataxia and paroxysmal torticollis could be an early symptom of CACNA1A-related disease. ${ }^{15)}$ Alternating hemiplegia is associated with ATP1A3 gene mutation, which encodes the $\alpha 3$ subunit of $\mathrm{Na}+/ \mathrm{K}+$ ATPase. ${ }^{16)}$

Some PNE like breath-holding spells (BHS) might be linked to iron. Iron is known to play an important role as a cofactor in neurotransmitter synthesis and myelin formation, affecting neurodevelopment. ${ }^{17-21)}$ During the biosynthesis of catecholamines such as dopamine and adrenaline, iron acts as a cofactor, the deficiency of which can alter the dopamine synthesis pathway. ${ }^{19)}$ It has also been found that iron has a similar functional structure to that of dopamine D2 receptor and a study of iron-deficient mice demonstrated a decreased dopamine D2 receptor density in the striatum. ${ }^{22,23)}$ Iron deficiency in the central nervous system leads to decreased activation of dopamine $\mathrm{D} 2$ receptors, which can disrupt suppression via the negative feedback and cause hyperkinetic movement disorders. ${ }^{24)}$

There is also a possible link to oxidant status. Oxidative stress can affect the occurrence of neurological disorders. ${ }^{25,26}$ In a study of 31 patients with BHS, the plasma total antioxidant capacity was shown to be significantly low and the total oxidant status and oxidative stress index were higher relative to healthy controls $(P \leq 0.01)$. The authors believed that in BHS patients, increased oxidative stress could deteriorate catecholamine metabolism and neurotransmitter function and that inadequate regulation of the autonomic nervous system may have increased the oxidative stress. $^{27)}$

In the 1990s, studies were conducted to determine the serum levels of cortisol and prolactin in PNE patients. ${ }^{28,29)}$ Groups of 50 patients with epilepsy, febrile seizure, syncope, and BHS were compared with 53 controls. The prolactin level was high in the epilepsy group, while the cortisol level increased in the epilepsy and febrile seizure groups. ${ }^{28)}$ Other studies examined 37 patients with epilepsy, febrile seizure, and syncope and 37 healthy controls. Prolactin increased in the epilepsy group, whereas cortisol showed a nonspecific increase. ${ }^{29)}$ Convulsive seizures may induce the release of prolactin via the activation of the hypothalamicpituitary axis. Sims et al. ${ }^{30)}$ found higher levels of measured serum norepinephrine in newborns with jitteriness, of unknown origin, than in the control group, but could not elucidate a clear mechanism.

\section{Diagnostic strategy}

The PNE behavior in infants is highly diversified. Most of these events are characterized by various clinical symptoms induced by physiological processes and which are far from being characteristics of a seizure. Since the differences are very subtle and at times difficult to discern, both the situations are likely to be confused with. In children, the incidence of PNE is much higher, about 10 times that of seizure. Tests must be conducted and interpreted properly, considering the condition and circumstances of the patient, to exclude epilepsy and other organic diseases such as neurosurgical, metabolic, heart, and digestive disorders. To detect epileptic seizure, brain waves are the most important parameters and video electroencephalography (EEG) monitoring is the most useful test. ${ }^{3-6)}$

Parents are referred to pediatric units when their child exhibits unusual symptoms. The pediatrician must take a detailed patient history and carefully examine the primary symptom and present illness. The pediatrician should inspect the video taken by the parents, if available, and, if not, should ask them to take a video recording the next time the symptoms develop. Using video recordings to verify the symptoms enhances not only the diag. nostic accuracy but is also cost-effective. ${ }^{31)}$ Moreover, birth history, past history (trauma, chronic illness, etc.) and family history need to be considered. The doctor should check whether the child's growth and development are normal for his or her 
age and should conduct an age-appropriate neurological exam. Basic tests to be done include a blood test (complete blood cell count, electrolyte, iron study, ionized/total calcium) and an EEG. The possibility of a provoked seizure can be detected by checking the electrolyte and calcium levels. Some studies suggest that low iron levels (ferritin $<10 \mathrm{ng} / \mathrm{mL}$, iron $<22 \mu \mathrm{g}$ / $\mathrm{dL}$, transferrin saturation $<16 \%$ ) may be associated with PNE, which can thus be tested. ${ }^{18,23)}$ The prolactin level can also help identify seizures. ${ }^{28,29)}$ If there is an unusual finding in the neurological exam, cranial ultrasonography, or brain MRI may also be considered. If an arrhythmia is suspected, a 24hour Holter monitoring may be considered as well. In hospitals where (portable) video-EEG is possible, the video-EEG can be performed prior to the routine EEG, but (in the case of Korea) routine EEG is sometimes performed first when the health insurance criteria are not met. If the routine EEG reveals no abnormality and if the symptom is hard to differentiate from a seizure and occurs frequently, then a video-EEG may help with the diagnosis. ${ }^{5,32)}$ Finally, if all the test and circumstances are normal, then we can diagnose and differentiate specific PNE (Fig. 1).

\section{Specific PNE}

In infants, there are various classes of PNE. Grossly, we can classify PNE by the age of onset such as neonate, early infancy (0-6 months), and late infancy (6-12 months). However, some overlaps might exist between them. This article explains the typical PNE (Table 2). 5,9,33-38)

\section{Neonate}

\section{Jitteriness}

Jitteriness is a phenomenon frequently observed in newborns. It is characterized by involuntary and rhythmic tremors in the limbs close to the body's central axis that ceases when held

Table 2. Common paroxysmal nonepileptic events in infants

\begin{tabular}{ll}
\hline Onset & Possible associated situation \\
\hline Neonate & Crying, stimulation \\
Jitteriness & $\begin{array}{l}\text { Sleep } \\
\text { Neonatal sleep myoclonus }\end{array}$ \\
Hyperekplexia & Sbrupt stimulation \\
Sleep apnea & \\
Early infancy (0-6 months) & Excitement, frustration \\
Shivering & \\
Benign infantile myoclonus & \\
Benign paroxysmal tonic upgaze with ataxia & \\
Paroxysmal torticollis & \\
Self-stimulation & Facial flushing, diaphoresis, \\
Late infancy (6-12 months) & grunting \\
Breath-holding spell & \\
Spasmus nutans & Crying \\
Stereotypes & \\
Body rocking/head banging & Excitation, stress \\
Alternating hemiplegia & \\
Other & \\
Sandifer syndrome & \\
Extrapyramidal symptoms to drug & \\
\hline
\end{tabular}

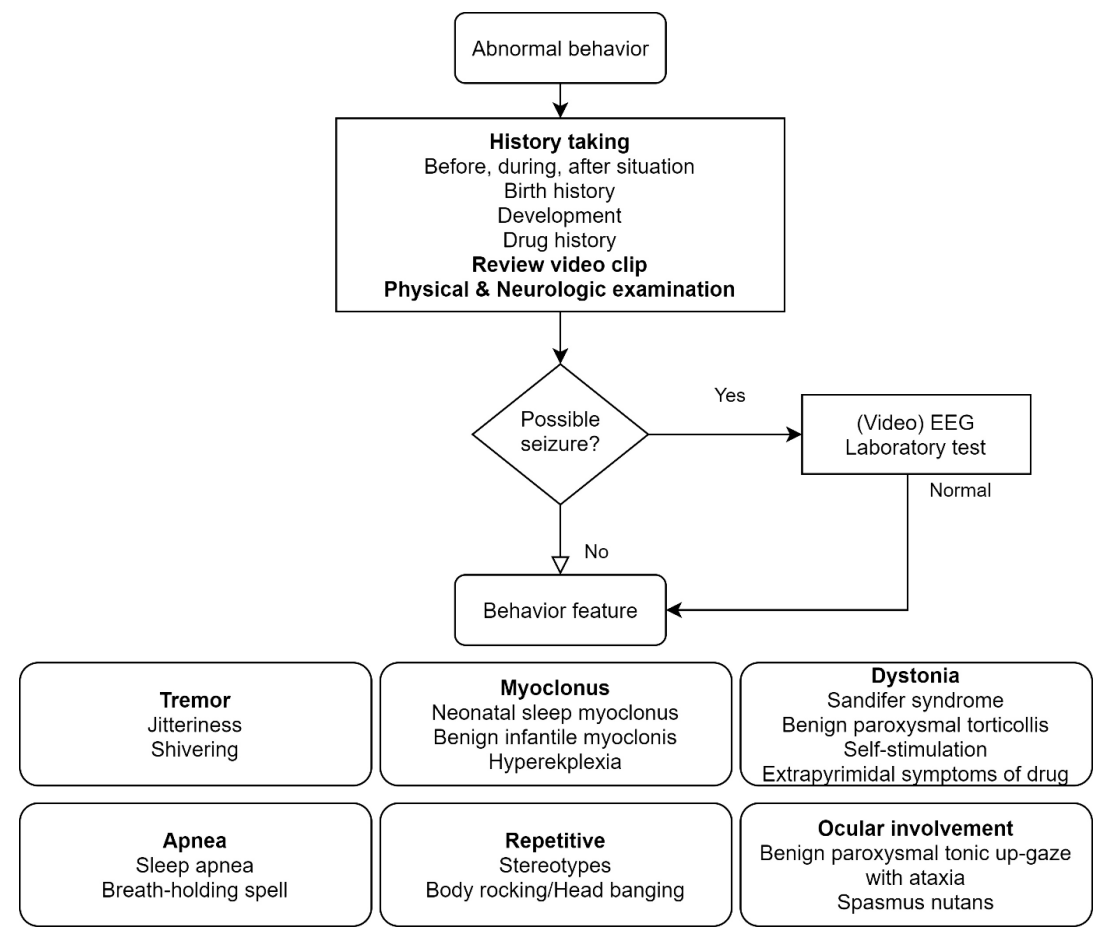

Fig. 1. Diagnostic approach to paroxysmal nonepileptic events. EEG, electroencephalography. 
firmly. ${ }^{39)}$ In an observational study of healthy newborns, tremors were observed in $44 \%$ of cases. ${ }^{40)}$ Tremors can be observed when the baby cries heavily, mostly at a high frequency of $\geq 6 \mathrm{~Hz}$ and low amplitude of $<3 \mathrm{~cm}$. Such fine tremors are related to crying and in many cases, symptoms improve by soothing or breastfeeding the baby. Tremors may sometimes resemble a clonus or myoclonus, but there are some differences. Tremors are generally of a higher frequency and lower amplitude. Seizures are characterized by faster movements with a slow rebound. ${ }^{17)}$

Neonatal jitteriness can be divided into 3 groups: (1) mild: tremor is observed only when the baby is crying; (2) moderate: tremor is observed as the baby wakes up from sleep; (3) severe: tremor is observed even when the baby is sleeping quietly or awake. ${ }^{40)}$ Severe tremors can occur due to metabolic disorders such as hypoglycemia or hypocalcemia, systemic problems such as infection or thyroid disease and nervous system damage such as hypoxic-ischemic encephalopathy or intraventricular hemorrhage. ${ }^{41-43)}$ In about half the cases, tremors begin after the first day of birth and last for an average of 7.2 months, even longer if the tremor is more severe. Late symptom onset does not yield any significant differences from when symptoms started from postnatal day $1 .^{39)}$

In most cases, tremor is the only symptom, the cause of which is not clear. Fine tremor may be interpreted as excessive movement, low threshold to reflexes or exaggerated Moro reflexes. A study reported that these patients displayed poor visual monitoring abilities, high muscle tones (34\%) and hyperactive deep tendon reflexes $(52 \%) .{ }^{39)}$ Tests to determine the cause of tremors often do not reveal unusual findings. One study found that serum norepinephrine was higher in infants with tremors than infants who were asymptomatic, while epinephrine levels were similar. ${ }^{36}$ Immaturity of the nervous system may affect the pathogenesis of tremor. Increased sensitivity in the afferent terminal of the muscle spindle may cause brief muscle contractions and hence, the tremor can gradually disappear as the inhibitory pathway matures. ${ }^{39)}$

There are several factors associated with tremor, such as history of maternal or perinatal illness including maternal diabetes, thyrotoxicosis, sepsis, hemorrhage, use of anesthetics or other drugs, difficult labor, fetal distress, and placental insufficiency. About $75 \%$ of preterm infants associated with preeclampsia exhibited tremors, while magnesium sulfate injection had no effect. ${ }^{43)}$ If the mother takes drugs such as serotonin reuptake inhibitors (fluoxetine, fluvoxamine, sertraline), haloperidol, benzodiazepines, opiates, cannabinoids, and cocaine, the newborn may display hyperexcitability and tremors due to withdrawal and thus, care must be taken. Breastfeeding habits should also be checked. Chocolate, caffeine, and mate tea may be associated with hyperexcitability in infants. ${ }^{44,45)}$ Factors such as vitamin D deficiency, carminative, heavy metal, and pesticides must also be considered. . $2,46-48)^{2}$

Patients without a history of critical perinatal illness are known to have good prognosis. At postnatal 9 months, tremors disappear in about $70 \%$ of the patients and normal development was confirmed after 2 years. ${ }^{47)}$ Since newborns with perinatal risk factors have approximately $30 \%$ risk of developing neurodevelopmental disorders, special care must be taken if these risk factors are accompanied by symptoms of hyperexcitability syndrome. ${ }^{49)}$

\section{Neonatal sleep myoclonus}

Since 1982, neonatal sleep myoclonus has been commonly reported in several different countries and more commonly in male infants. ${ }^{50,51)}$ It may be mistaken for neonatal seizure. ${ }^{52)}$ In one report, $96 \%$ of the cases were term infants and $4 \%$ were near-term infants. ${ }^{51)} \mathrm{In}$ a study of 38 infants, only 2 infants were born at 36 weeks of gestation and the rest were term infants. ${ }^{52,53)}$ Since it is not likely to occur in a highly premature brain, it may be linked to brain maturation.

Sleep myoclonus typically begins before the age of 2 weeks after birth. In a study of 12 infants, myoclonus began at 1-15 days after birth and lasted for 6.3 days on an average and rarely after 8 weeks of birth. ${ }^{52,54)}$ Myoclonus tends to increase for up to $3-4$ weeks of birth and then decreases until 6 years of age in nearly $95 \%$ of cases. ${ }^{51,53,55,56)}$ Myoclonus occurs primarily during Non-rapid eye movement (NREM) sleep with a frequency of 20-30 per minute persisting for $\leq 1$ hour on an average. ${ }^{51,57)}$

Myoclonus is characterized by shaking of the body during sleep. Clinically, it is commonly observed during stages II-III of NREM sleep on both sides, which disappears completely when awakened. ${ }^{55)}$ Myoclonus usually appears in the arms and legs either synchronously or asynchronously. It appears across multiple parts or the entire body and rarely in a single body part. It is not commonly observed in the face, head, or abdominal area. ${ }^{54,55)} \mathrm{It}$ is sometimes induced by stimuli such as sounds and shaking.

In a study of EEG monitoring in 18 infants, myoclonus was found in 17 infants. Four infants had a history of receiving treatment after being misdiagnosed with seizure. In all 18 patients, EEG was normal and myoclonus was observed during sleep, but in 2 of them, it was also observed during the transition from sleep to awakening. ${ }^{50)}$ Similar findings have been observed in other studies and in as many as 33\% of the cases, it is confused with epilepsy. ${ }^{57)}$

EEG results are usually normal and video-EEG monitoring has been recently recommended for diagnosis. ${ }^{12)}$ Differential diagnosis includes tremor, provoked seizure (hypoglycemia, hypocalcemia, meningitis, hemorrhage, pyridoxine deficiency, and drug withdrawal), and hyperreactivity. Less common diagnosis made from the first day of birth includes benign familial neonatal epilepsy and idiopathic neonatal epilepsy, with normal findings in the neurological exam and interictal EEG. In severe cases of epileptic encephalopathy such as early myoclonic encephalopathy and early infantile epileptic encephalopathy, abnormal findings are found in neurological exams or EEGs. ${ }^{51)}$

Sleep myoclonus shows good clinical progress and disappears after about 5 years of follow-up without any developmental abnormalities. ${ }^{51,56)}$ No special treatment is required, but benzo- 
diazepine can increase the frequency of myoclonus. ${ }^{57)}$ Although the pathogenesis of neonatal sleep myoclonus remains unclear, activation of the reticular system and imbalance of the serotonergic system may be implicated. Recent studies have reported a pattern of migraine-related autosomal dominant inheritance, with an unclear link to the KCNQ2 and KCNQ3 genes. ${ }^{58)}$

\section{Hyperekplexia}

Hyperekplexia was first reported in 1958 as a rare condition of hypertonia due to the awakening from hypotonia during sleep or external stimuli. It can occur by birth or later in life, accompanied by a startle in the mild case. In severe cases, apnea and cyanosis as well as hypertonia in the limbs are observed for several seconds. It may be induced by abrupt acoustics and visual stimuli. EEG is normal. Central apnea-induced brainstem dysfunction and laryngospasm-induced peripheral apnea, aspiration, and heart block can lead to sudden infant death. Hypertonia improves with age and the tone becomes normal by the age of 3 , but it may recur in adolescence or adulthood due to sudden stimuli, cold, or pregnancy. Intellectual abilities are intact and patients may respond to low doses of clonazepam, valproic acid, and levetiracetam. Some cases may be accompanied by a developmental delay or cerebral impairment requiring close monitoring. ${ }^{59,60)}$

\section{Sleep apnea}

It is defined as having a minimum of 10 - to 15 -second intervals between breaths during sleep. It is frequently observed during the first 2 months of life in premature infants. It can be caused by a premature brain, gastroesophageal reflux, or drug therapy. In some cases, it occurs in association with epilepsy but the cause is usually unknown. Since it can lead to sudden infant death in severe cases, continuous monitoring may be required for several months until symptoms improve. ${ }^{61,62)}$

\section{Early infancy}

\section{Shivering}

Shivering is a short-lived paroxysmal behavior that begins at around 3-4 months of age, but can continue to occur frequently throughout infancy. It is characterized by rapid tremors for a short period of time without the loss of consciousness. In particular, it may involve flexion or extension of the head and neck with stiffness and tremor in the head/neck. It may have a trigger, reoccur several times a day, and be accompanied by no subsequent loss of consciousness. EEG is normal with symptoms confirmed. ${ }^{63)}$

\section{Benign infantile myoclonus}

It is usually observed between 3-9 months of age, but may begin from the neonatal period. The infant, while awakening, may exhibit neck flexion/extension or limb extension similar to the spasms in West syndrome. Symptoms can appear several times a day, sometime similar to myoclonus of the whole body. EEG and developmental status are normal. In many cases, symptoms naturally disappear at around 9 months. It is frequently observed in excessively stimulated children, but the cause remains unclear. ${ }^{57,64)}$

\section{Benign paroxysmal tonic upgaze with ataxia}

The symptoms begin between 3 months and 2 years of age, characterized by ataxia and upward deviation of the eyes lasting transiently or continuously (from several seconds to days). While the symptoms are present, if the child tries to look downward, nystagmus and head flexion are induced in the same direction to compensate for the deviation. Symptoms disappear during sleep and may worsen when tired or infected. They disappear spontaneously within a few years and developmental or language delays may be observed in about half of the cases. The etiology is unknown. L-dopa improves the symptoms in some patients. Neuroimaging results are normal with a possible family history. ${ }^{65,66)}$

\section{Paroxysmal torticollis}

It begins in the first year of life and disappears spontaneously around 3-5 years of age. Symptoms include repeated painless torticollis induced by change in posture, sometimes preceded by abnormal nystagmus. While the symptoms are present, the infant may undergo discomfort, whining, hypersensitivity, pallidness, or ataxia. Symptoms may originate from one side and migrate to the other, lasting several minutes, hours, or sometimes even days. They appear spontaneously and can be repeated at varying frequencies. The results of neurological exam, brain MRI and EEG are normal in-between symptoms. It occurs more frequently in female infants and in the morning. Although the exact cause is unknown, it sometimes progresses to dizziness, headache, and ataxia, suggesting a link to channelopathy or migraine. ${ }^{67-69)}$

\section{Self-stimulation}

It begins between 3 months and 5 years of age and may be manifested in various forms such as dystonia, grunting, sweating, cyanosis, pallidness, and pelvic movements. Some infants shake the pelvis or stimulate the genitalia either directly or by rubbing with their thighs. Infants exhibit this behavior when they are tired or bored and before falling asleep. The behavior stops when their attention is diverted. It helps to have the caregiver take a video using a cell phone, to be used for diagnosis. The prognosis is good. ${ }^{70)}$

\section{Late infancy}

\section{Breath-holding spells}

This is one of the most common types of PNE in infants. It generally appears between $6-18$ months of age and may begin earlier or last until later. These are classified into 2 types: pallid and cyanotic. The pallid type is a vasovagal syncope induced by a neurologically-mediated cardio-inhibitory mechanism. It can be caused by a head trauma where the infant becomes unconscious, 
limp, and pale. In some cases, it is not induced by trauma and may be accompanied by myoclonus. Recovery can take a few seconds to 2 minutes. Some infants may have iron deficiency or irondeficiency anemia. The cyanotic type is caused by expiratory apnea lasting for a long time. Symptoms include crying or screaming, apnea, loss of consciousness, cyanosis, and stiffness. It is caused by minor trauma, fear, or irritation. The cyanotic type is more common than the pallid type and family history is observed in both types. Symptoms improve with age. No special treatment is required other than reassuring the caregiver. ${ }^{62,71)}$ Since there is a possible link to iron-related mechanisms, iron is supplemented in BHS. ${ }^{24,72)}$ If symptoms are severe, other drugs can be tried. Studies of treatment modalities are shown in Table $3 .{ }^{73-84)}$

\section{Spasmus nutans}

Head tilt, nodding, or shaking movements are observed as well as characteristic symptoms such as asymmetric nystagmus. It lasts for several seconds and tends to repeat. It starts to decline around the age of one and disappears between the ages of 3 and 6. EEG is normal. If symptoms persist, video monitoring must be conducted to rule out the possibility of chiasmatic or diencephalic lesions. ${ }^{85)}$

\section{Stereotypes}

This refers to repetitive movements such as shaking of the hand or leg. It is also observed in healthy infants and more prominently under excitation or stress. Symptoms often improve at around 2-3 years of age. Symptoms are more marked and persistent in neurological disorders such as intellectual disability or autism. ${ }^{86}$

\section{Body rocking/head banging}

This behavior is characterized by repeated rocking of the body or head. It is observed during daytime activity and also during a nap or nighttime sleep. There can be 1 or 2 motions every 1-2 seconds and the behavior lasts for up to 15 minutes. The behavior is not observed when asleep. It can occur in about 5\% of healthy infants, but since it can also be observed in infants with developmental disorders or autism, treatment is necessary if symptoms persist abnormally. ${ }^{87-91)}$

\section{Alternating hemiplegia}

It often begins before 18 months of age. Subacute flaccid hemiparesis is accompanied by autonomic nervous symptoms and unilateral nystagmus on the paretic side. Symptoms arise with a sense of fear or excitation along with a rigid or dystonic posture. The head is deviated towards the symptomatic side and as it later progresses to complete hemiplegia, swallowing and breathing become difficult. Hemiplegia can last for several minutes to hours and affects both sides at the same time. Symptoms improve spontaneously to achieve complete recovery after sleep. Symptoms may resemble Todd's paralysis or transient ischemia after initial local seizure. EEG conducted while the symptoms are present may reveal a slow wave lateralized to one hemisphere. As the patient ages, symptoms tend to improve, but they may develop cognitive decline, epilepsy, ataxia, choreoathetosis, or heart problems. Flunarizine may improve the symptoms, but cannot prevent seizures or neurological abnormalities. ${ }^{92)}$

\section{Other}

\section{Sandifer syndrome}

Infants may periodically exhibit abnormal posture of the neck, trunk, and limbs due to gastroesophageal reflux, hiatal hernia, or esophagus dysfunction. They may display a sudden

Table 3. Studies of treatment modalities for breath-holding spells

\begin{tabular}{|c|c|c|c|c|c|c|c|}
\hline Study & Study type & Case size & Case selection & Age (mo) & Dose (mg/kg/day) & Duration (mo) & Response rate (\%) \\
\hline \multicolumn{8}{|l|}{ Iron } \\
\hline Dai and Demiryurek ${ }^{73)}(2020)$ & PP & 34 & IDA & $12-48$ & 3 & 3 & 58.8 \\
\hline Bidabadi et al. $^{74)}$ (2019) & PP & 42 & All & $6-24$ & 6 & 3 & 92.9 \\
\hline Gurbuz et al. $^{75)}$ (2018) & PP & 312 & All & $1-48$ & 4 & 3 & 86.2 \\
\hline Jain et al. $^{76)}(2017)$ & PP & 100 & ID or IDA & $6-36$ & 3 & 3 & 94.8 \\
\hline Mocan et al. ${ }^{77)}(1999)$ & PP & 63 & IDA & $6-40$ & 6 & 3 & 84.0 \\
\hline Daoud et al. $^{78)}$ (1997) & $\mathrm{RCT}$ & 33 & All & 14.8 (mean) & 5 & 4 & 87.9 \\
\hline \multicolumn{8}{|l|}{ Piracetam } \\
\hline Dai and Demiryurek ${ }^{73)}(2020)$ & PP & 34 & No anemia & $12-48$ & 40 & 3 & 8.8 \\
\hline Abbaskhanian et al. ${ }^{79)}(2012)$ & RCT & 150 & All & $6-60$ & 40 & 3 & 91.0 \\
\hline Sawires and Botrous ${ }^{80)}(2012)$ & RCT & 40 & All & $6-60$ & 50 & 4 & 83.9 \\
\hline Donma $^{81)}(1998)$ & RCT & 76 & All & & 40 & 2 & 92.3 \\
\hline \multicolumn{8}{|l|}{ Theophylline } \\
\hline Dai and Demiryurek ${ }^{73)}(2020)$ & PP & 35 & No anemia & $12-48$ & 10 & 3 & 82.9 \\
\hline Garg and Goraya $^{82)}$ (2015) & Case & 1 & & 120 & $200 \mathrm{mg}$ & 18 & \\
\hline Carano et al. ${ }^{83)}$ (2013) & Case & 1 & & 13 & 160 mg+glycopyrrolate & 17 & \\
\hline \multicolumn{8}{|l|}{ Atropine } \\
\hline Gonzalez Corcia et al. ${ }^{84)}$ (2018) & PP & 45 & Pallid spell & 4-18 & 0.02 & 3 & 75 \\
\hline
\end{tabular}

ID, iron deficiency; IDA, iron-deficiency anemia; PP, pre-post study; RCT, randomized controlled trial. 
deviation of the head, tension in the entire body or opisthotonus. There may be tremors in the limbs, with eyes fixed and pause in breathing. Typically, it occurs few minutes after a meal and may not be accompanied by a reflux. If there are no symptoms, then it is normal. It is likely to occur especially between 18 and 36 months of age. It may resemble an epileptic seizure or dystonia. If the EEG is normal and reflux is confirmed, then epilepsy can be ruled out. Treating gastroesophageal reflux helps to improve the symptoms. ${ }^{93-96)}$

\section{Extrapyramidal symptoms to drugs}

It may appear across all age groups but more commonly in infants. Various drugs can induce acute and transient idiopathic responses similar to epileptic seizures. The most common symptom is abnormal muscle tone around the neck, face, or lip area. Commonly associated drugs include metoclopramide, cisapride, and neuroleptics. ${ }^{97,98)}$ If symptoms are suspected, biperiden or lorazepam can be used. ${ }^{99}$ To prevent recurrence, the drugs taken must be identified and the caregiver or hospital that prescribed the drugs must be notified.

\section{Conclusions}

Most PNE show benign progress as previously described. Therefore, it is important to inform and reassure the caregivers that it is not a seizure. Video clips taken by caregivers may serve as highly critical evidence for diagnosis. If a seizure is not strongly suspected after checking the history, watching the prepared video clip will help reduce unnecessary testing. If the possibility of seizure cannot be completely ruled-out, verification by EEG is necessary. The symptoms of PNE vary by age, but since most of them disappear without after-effects, it is most important to make an accurate diagnosis through careful monitoring and examination, before considering whether to use an antiepileptic drug or not.

\section{Footnotes}

Conflicts of interest: No potential conflict of interest relevant to this article was reported.

Acknowledgments: This work was supported by the research fund of Chungnam National University (2018-1299-01).

\section{References}

1. Berg AT, Shinnar S. The risk of seizure recurrence following a first unprovoked seizure: a quantitative review. Neurology 1991;41:965-72.

2. Fisher RS, Acevedo C, Arzimanoglou A, Bogacz A, Cross JH, Elger CE, et al. ILAE official report: a practical clinical definition of epilepsy. Epilepsia 2014;55:475-82.

3. Stroink H, van Donselaar CA, Geerts AT, Peters AC, Brouwer OF, Arts WF. The accuracy of the diagnosis of paroxysmal events in children.
Neurology 2003;60:979-82.

4. Cross JH. Differential diagnosis of epileptic seizures in infancy including the neonatal period. Semin Fetal Neonatal Med 2013;18:192-5.

5. Beach R, Reading R. The importance of acknowledging clinical uncertainty in the diagnosis of epilepsy and non-epileptic events. Arch Dis Child 2005;90:1219-22.

6. Shuper A, Mimouni M. Problems of differentiation between epilepsy and non-epileptic paroxysmal events in the first year of life. Arch Dis Child 1995;73:342-4.

7. Cuvellier JC, Lepine A. Childhood periodic syndromes. Pediatr Neurol 2010;42:1-11.

8. DiMario FJ Jr. Paroxysmal nonepileptic events of childhood. Semin Pediatr Neurol 2006;13:208-21.

9. Kotagal P, Costa M, Wyllie E, Wolgamuth B. Paroxysmal nonepileptic events in children and adolescents. Pediatrics 2002;110:e46.

10. Paolicchi JM. The spectrum of nonepileptic events in children. Epilepsia 2002;43 Suppl 3:60-4.

11. Joseph J. Volpe TEI, Basil T. Darras. Volpe`s neurology of the newborn. 6th ed. Philadelphia (PA): Elsevier, 2018.

12. Kuiper MJ, Brandsma R, Lunsing RJ, Eggink H, Ter Horst HJ, Bos AF, et al. The neurological phenotype of developmental motor patterns during early childhood. Brain Behav 2019;9:e01153.

13. Bonnet C, Roubertie A, Doummar D, Bahi-Buisson N, Cochen de Cock V, Roze E. Developmental and benign movement disorders in childhood. Mov Disord 2010;25:1317-34.

14. Garone G, Capuano A, Travaglini L, Graziola F, Stregapede F, Zanni G, et al. Clinical and genetic overview of paroxysmal movement disorders and episodic ataxias. Int J Mol Sci 20;21:3603.

15. Roubertie A, Echenne B, Leydet J, Soete S, Krams B, Rivier F, et al. Benign paroxysmal tonic upgaze, benign paroxysmal torticollis, episodic ataxia and CACNA1A mutation in a family. J Neurol 2008;255:1600-2.

16. Capuano A, Garone G, Tiralongo G, Graziola F. Alternating hemiplegia of childhood: understanding the genotype-phenotype relationship of ATP1A3 variations. Appl Clin Genet 2020;13:71-81.

17. El Hamdouchi A, El Kari K, Rjimati L, El Haloui N, El Mzibri M, Aguenaou $\mathrm{H}$, et al. Impact of flour fortification with elemental iron on the prevalence of anaemia among preschool children in Morocco. East Mediterr Health J 2010;16:1148-52.

18. Zehetner AA, Orr N, Buckmaster A, Williams K, Wheeler DM. Iron supplementation for breath-holding attacks in children. Cochrane Database Syst Rev 2010:CD008132.

19. Algarin C, Nelson CA, Peirano P, Westerlund A, Reyes S, Lozoff B. Irondeficiency anemia in infancy and poorer cognitive inhibitory control at age 10 years. Dev Med Child Neurol 2013;55:453-8.

20. Uldall P, Alving J, Hansen LK, Kibaek M, Buchholt J. The misdiagnosis of epilepsy in children admitted to a tertiary epilepsy centre with paroxysmal events. Arch Dis Child 2006;91:219-21.

21. Trimm F. Neuropsychosocial deficits associated with iron deficiency: how long do they last? J Pediatr 2013;163:1242-3.

22. Connor JR, Menzies SL. Cellular management of iron in the brain. J Neurol Sci 1995;134 Suppl:33-44.

23. Orii KE, Kato Z, Osamu F, Funato M, Kubodera U, Inoue R, et al. Changes of autonomic nervous system function in patients with breath-holding spells treated with iron. J Child Neurol 2002;17:337-40.

24. Bressman SB, Greene PE. Treatment of hyperkinetic movement disorders. Neurol Clin 1990;8:51-75.

25. Patel M, Li QY. Age dependence of seizure-induced oxidative stress. Neuroscience 2003;118:431-7.

26. Salim S. Oxidative stress and the central nervous system. J Pharmacol Exp Ther 2017;360:201-5.

27. Calik M, Abuhandan M, Aycicek A, Taskin A, Selek S, Iscan A. Increased oxidant status in children with breath-holding spells. Childs Nerv Syst 2013;29:1015-9.

28. Zelnik N, Kahana L, Rafael A, Besner I, Iancu TC. Prolactin and cortisol levels in various paroxysmal disorders in childhood. Pediatrics 1991;88: 486-9.

29. Dirik E, Sen A, Anal O, Cevik NT. Serum cortisol and prolactin levels in 
childhood paroxysmal disorders. Acta Paediatr Jpn 1996;38:118-20.

30. Sims M, Artal R, Quach H, Wu PY. Neonatal jitteriness of unknown origin and circulating catecholamines. J Perinat Med 1986;14:123-6.

31. Huang LL, Wang YY, Liu LY, Tang HP, Zhang MN, Ma SF, et al. Home videos as a cost-effective tool for the diagnosis of paroxysmal events in infants: prospective study. JMIR Mhealth Uhealth 2019;7:e11229.

32. Canavese C, Canafoglia L, Costa C, Zibordi F, Zorzi G, Binelli S, et al. Paroxysmal non-epileptic motor events in childhood: a clinical and videoEEG-polymyographic study. Dev Med Child Neurol 2012;54:334-8.

33. Park EG, Lee J, Lee BL, Lee M, Lee J. Paroxysmal nonepileptic events in pediatric patients. Epilepsy Behav 2015;48:83-7.

34. Kim SH, Kim H, Lim BC, Chae JH, Kim KJ, Hwang YS, et al. Paroxysmal nonepileptic events in pediatric patients confirmed by long-term videoEEG monitoring--Single tertiary center review of 143 patients. Epilepsy Behav 2012;24:336-40.

35. Hamiwka LD, Singh N, Niosi J, Wirrell EC. Diagnostic inaccuracy in children referred with "first seizure": role for a first seizure clinic. Epilepsia 2007;48:1062-6.

36. Bye AM, Kok DJ, Ferenschild FT, Vles JS. Paroxysmal non-epileptic events in children: a retrospective study over a period of 10 years. J Paediatr Child Health 2000;36:244-8.

37. Desai P, Talwar D. Nonepileptic events in normal and neurologically handicapped children: a video-EEG study. Pediatr Neurol 1992;8:127-9.

38. Bye AM, Nunan J. Video EEG analysis of non-ictal events in children. Clin Exp Neurol 1992;29:92-8.

39. Shuper A, Zalzberg J, Weitz R, Mimouni M. Jitteriness beyond the neonatal period: a benign pattern of movement in infancy. J Child Neurol 1991;6:243-5.

40. Parker S, Zuckerman B, Bauchner H, Frank D, Vinci R, Cabral H. Jitteriness in full-term neonates: prevalence and correlates. Pediatrics 1990;85: 17-23.

41. Berger A, Sharf B, Winter ST. Pronounced tremors in newborn infants: their meaning and prognostic significance. A long-term follow-up study of 30 such infants. Clin Pediatr (Phila) 1975;14:834-5.

42. Collins M, Young M. Benign neonatal shudders, shivers, jitteriness, or tremors: early signs of vitamin D deficiency. Pediatrics 2017;140:e20160719.

43. Ozkan H, Anal O, Turan A, Giray O. Maternal preeclampsia and jitteriness in preterm infants. Pediatr Int 1999;41:557-60.

44. Cambria S, Manganaro R, Mami C, Marseglia L, Gemelli M. Hyperexcitability syndrome in a newborn infant of chocoholic mother. Am J Perinatol 2006;23:421-2.

45. Martin I, Lopez-Vilchez MA, Mur A, Garcia-Algar O, Rossi S, Marchei E, et al. Neonatal withdrawal syndrome after chronic maternal drinking of mate. Ther Drug Monit 2007;29:127-9.

46. Ize-Ludlow D, Ragone S, Bruck IS, Bernstein JN, Duchowny M, Pena BM. Neurotoxicities in infants seen with the consumption of star anise tea. Pediatrics 2004;114:e653-6.

47. Leone D, Brogna C, Ricci D, Romeo DM, Leo G, Serrao F, et al. Development of clinical signs in low risk term born infants with neonatal hyperexcitability. Early Hum Dev 2013;89:65-8.

48. Olympio KP, Goncalves CG, Salles FJ, Ferreira AP, Soares AS, Buzalaf MA, et al. What are the blood lead levels of children living in Latin America and the Caribbean? Environ Int 2017;101:46-58.

49. Huntsman RJ, Lowry NJ, Sankaran K. Nonepileptic motor phenomena in the neonate. Paediatr Child Health 2008;13:680-4.

50. Kaddurah AK, Holmes GL. Benign neonatal sleep myoclonus: history and semiology. Pediatr Neurol 2009;40:343-6.

51. Maurer VO, Rizzi M, Bianchetti MG, Ramelli GP. Benign neonatal sleep myoclonus: a review of the literature. Pediatrics 2010;125:e919-24.

52. Goraya JS, Singla G, Mahey H. Benign neonatal sleep myoclonus: frequently misdiagnosed as neonatal seizures. Indian Pediatr 2015;52:713-4.

53. Paro-Panjan D, Neubauer D. Benign neonatal sleep myoclonus: experience from the study of 38 infants. Eur J Paediatr Neurol 2008;12:14-8.

54. Resnick TJ, Moshe SL, Perotta L, Chambers HJ. Benign neonatal sleep myoclonus. Relationship to sleep states. Arch Neurol 1986;43:266-8.

55. Di Capua M, Fusco L, Ricci S, Vigevano F. Benign neonatal sleep myoclonus: clinical features and video-polygraphic recordings. Mov Disord
1993;8:191-4

56. Suzuki Y, Toshikawa H, Kimizu T, Kimura S, Ikeda T, Mogami Y, et al. Benign neonatal sleep myoclonus: our experience of 15 Japanese cases. Brain Dev 2015;37:71-5.

57. Caraballo RH, Capovilla G, Vigevano F, Beccaria F, Specchio N, Fejerman $\mathrm{N}$. The spectrum of benign myoclonus of early infancy: Clinical and neurophysiologic features in 102 patients. Epilepsia 2009;50:1176-83.

58. Afawi Z, Bassan H, Heron S, Oliver K, Straussberg R, Scheffer I, et al. Benign neonatal sleep myoclonus: an autosomal dominant form not allelic to KCNQ2 or KCNQ3. J Child Neurol 2012;27:1260-3.

59. Praveen V, Patole SK, Whitehall JS. Hyperekplexia in neonates. Postgrad Med J 2001;77:570-2.

60. Vigevano F, Lispi ML. Tonic reflex seizures of early infancy: an age-related non-epileptic paroxysmal disorder. Epileptic Disord 2001;3:133-6.

61. Obeid M, Mikati MA. Expanding spectrum of paroxysmal events in children: potential mimickers of epilepsy. Pediatr Neurol 2007;37:309-16.

62. Stephenson JB. Anoxic seizures: self-terminating syncopes. Epileptic Disord 2001;3:3-6.

63. Riehl JA, Mink JW. Shuddering attacks. J Pediatr Neurol 2010;8:25-7.

64. Fejerman N. Nonepileptic disorders imitating generalized idiopathic epilepsies. Epilepsia 2005;46 Suppl 9:80-3.

65. Campistol J, Prats JM, Garaizar C. Benign paroxysmal tonic upgaze of childhood with ataxia. A neuro-ophthalmological syndrome of familial origin? Dev Med Child Neurol 1993;35:436-9.

66. Zafeiriou DI. Paroxysmal tonic upward gaze of childhood "plus": an oculomotor channelopathy? Eur J Paediatr Neurol 2015;19:278-9.

67. Sanner G, Bergstrom B. Benign paroxysmal torticollis in infancy. Acta Paediatr Scand 1979;68:219-23.

68. Danielsson A, Anderlid BM, Stodberg T, Lagerstedt-Robinson K, Klackenberg Arrhenius E, Tedroff K. Benign paroxysmal torticollis of infancy does not lead to neurological sequelae. Dev Med Child Neurol 2018;60:12515.

69. Shin M, Douglass LM, Milunsky JM, Rosman NP. The genetics of benign paroxysmal torticollis of infancy: is there an association with mutations in the CACNA1A gene? J Child Neurol 2016;31:1057-61.

70. Rodoo P, Hellberg D. Girls who masturbate in early infancy: diagnostics, natural course and a long-term follow-up. Acta Paediatr 2013;102:762-6.

71. Leung AKC, Leung AAM, Wong AHC, Hon KL. Breath-holding spells in pediatrics: a narrative review of the current evidence. Curr Pediatr Rev 2019;15:22-9.

72. Lee J, Choi J, Kwon HH, Kang JW. Iron supplement in paroxysmal nonepileptic events in children. J Korean Child Neurol Soc 2017;25:146-50.

73. Dai AI, Demiryurek AT. Effectiveness oral theophylline, piracetam, and iron treatments in children with simple breath-holding spells. J Child Neurol 2020;35:25-30.

74. Bidabadi E, Poornabi Darzi S, Mashouf P, Shahraki T. Effectiveness of iron therapy on breath holding spells in the children. Iran J Child Neurol 2019; 13:155-61.

75. Gurbuz G, Perk P, Cokyaman T, Gurbuz OB. Iron supplementation should be given in breath-holding spells regardless of anemia. Turk J Med Sci 2019;49:230-7.

76. Jain R, Omanakuttan D, Singh A, Jajoo M. Effect of iron supplementation in children with breath holding spells. J Paediatr Child Health 2017;53: 749-53.

77. Mocan H, Yildiran A, Orhan F, Erduran E. Breath holding spells in 91 children and response to treatment with iron. Arch Dis Child 1999;81: 261-2.

78. Daoud AS, Batieha A, al-Sheyyab M, Abuekteish F, Hijazi S. Effectiveness of iron therapy on breath-holding spells. J Pediatr 1997;130:547-50.

79. Abbaskhanian A, Ehteshami S, Sajjadi S, Rezai MS. Effects of piracetam on pediatric breath holding spells: a randomized double blind controlled trial. Iran J Child Neurol 2012;6:9-15.

80. Sawires H, Botrous O. Double-blind, placebo-controlled trial on the effect of piracetam on breath-holding spells. Eur J Pediatr 2012;171:1063-7.

81. Donma MM. Clinical efficacy of piracetam in treatment of breath-holding spells. Pediatr Neurol 1998;18:41-5.

82. Garg M, Goraya JS. Treatment of cyanotic breath-holding spells with oral 
theophylline in a 10-year-old boy. J Child Neurol 2015;30:919-21.

83. Carano N, Bo I, Zanetti E, Tchana B, Barbato G, Agnetti A. Glycopyrrolate and theophylline for the treatment of severe pallid breath-holding spells. Pediatrics 2013;131:e1280-3.

84. Gonzalez Corcia MC, Bottosso A, Loeckx I, Mascart F, Dembour G, Francois G. Efficacy of treatment with belladonna in children with severe pallid breath-holding spells. Cardiol Young 2018;28:922-7.

85. Vigevano F. Non-epileptic paroxysmal disorders in the first year of life. In: Panayiotopoulos CP, editor. A practical guide to childhood epilepsies. Oxford: Medicinae, 2006:107-14.

86. Fernandez-Alvarez E. Transient benign paroxysmal movement disorders in infancy. Eur J Paediatr Neurol 2018;22:230-7.

87. Ryan NM. Body rocking, head banging, and head rolling: an analysis of rhythmic motor activities in normal infants. Pediatr Nurs 1983;9:281-5, 96.

88. Buyer LS, Berkson G, Winnega MA, Morton L. Stimulation and control as components of stereotyped body rocking. Am J Ment Defic 1987;91: 543-7.

89. Vinson RP, Gelinas-Sorell DF. Head banging in young children. Am Fam Physician 1991;43:1625-8.

90. Granana N, Tuchman RF. A child with severe head banging. Semin Pediatr Neurol 1999;6:221-4.

91. Berkson G, Andriacchi T. Body-rocking in college students and persons with mental retardation: characteristics, stability, and collateral behaviors. Res Dev Disabil 2000;21:13-29.

92. Panagiotakaki E, Gobbi G, Neville B, Ebinger F, Campistol J, Nevsimalova $\mathrm{S}$, et al. Evidence of a non-progressive course of alternating hemiplegia of childhood: study of a large cohort of children and adults. Brain 2010;133: 3598-610.

93. Somjit S, LeeY, Berkovic SF, Harvey AS. Sandifer syndrome misdiagnosed as refractory partial seizures in an adult. Epileptic Disord 2004;6:49-50.

94. Moore DM, Rizzolo D. Sandifer syndrome. JAAPA 2018;31:18-22.

95. Werlin SL, D'Souza BJ, Hogan WJ, Dodds WJ, Arndorfer RC. Sandifer syndrome: an unappreciated clinical entity. Dev Med Child Neurol 1980; 22:374-8.

96. Mindlina I. Diagnosis and management of Sandifer syndrome in children with intractable neurological symptoms. Eur J Pediatr 2020;179:243-50.

97. Hibbs AM, Lorch SA. Metoclopramide for the treatment of gastroesophageal reflux disease in infants: a systematic review. Pediatrics 2006;118: 746-52.

98. Mt-Isa S, Tomlin S, Sutcliffe A, Underwood M, Williamson P, Croft NM, et al. Prokinetics prescribing in paediatrics: evidence on cisapride, domperidone, and metoclopramide. J Pediatr Gastroenterol Nutr 2015;60: 508-14.

99. Chang MY, Lin KL, Wang HS, Wu CT. Drug-induced extrapyramidal symptoms at the Pediatric Emergency Department. Pediatr Emerg Care 2020;36:468-72.

How to cite this article: Jung SY, Kang JW. Is it really a seizure? The challenge of paroxysmal nonepileptic events in young infants. Clin Exp Pediatr 2021;64:384-92. https://doi.org/ 10.3345/cep.2020.00451 